\title{
THE WELFARE EFFECTS OF TOBACCO TAXATION: Estimates for 5 countries/regions
}

\author{
by \\ Deepak Lal \\ Hyongwon Kim \\ Gonglu Lu \\ Jordi Prat
}

UCLA Dept. of Economics Working Paper No.793

\begin{abstract}
This paper provides estimates of the economic welfare effects of tobacco taxation in India, S.Africa, S.Korea, Japan and the European Union. It argues that past studies of the cost-benefits of smoking are flawed as they fail to net out Pareto-irrelevant pecuniary externalities. It estimates tobacco demand for both the myopic and rational addiction models and finds the latter invariably perform better. It finds that the net welfare losses associated with (a) current tax levels (b)an increase over current taxation of $10 \%$ and (c) an increase of $10 \%$ a year for ! 0 years in all these countries, but particularly in the poorest, are large.
\end{abstract}

JEL classification: D61, H2, H31, I18, 012

Address :

8369 Bunche Hall

Dept. of Economics, UCLA, 405 Hilgard Ave.,

Los Angeles CA 90024

Tel: $310-8254521$

Fax: 310-925 9528

email: dlaleucla.edu 2000

March 
THE WELFARE EFFECTS OF TOBACCO TAXATION ${ }^{1}$ Estimates for 5 countries/regions

by

Deepak Lal, Hyongwon Kim, Gonglu Lu, Jordi Prat

INTRODUCTION

With the recent publication of the World Bank's report curbing the Epidemic-Government's and the economics of tobacco control (1999), and the issuance of a provisional draft for a WHO framework convention on tobacco control (WHO (2000)), the question of taxing tobacco in Third world countries is going to become an important policy issue. ${ }^{2}$ Surprisingly, much past work on the economics of smoking has not provided any estimates of the welfare effects of tobacco taxation using standard cost-benefit techniques. (see Chaloupka and Warner (1999) for a survey). This paper attempts to repair this omission by estimating these welfare effects of tobacco taxation in 3 developing countries (S.Korea, S. Africa and India) and two developed countries/ regions (Japan and the European Union).

Welfare estimates are made for three alternative levels of taxation: (a) the existing level of tobacco taxes, (b) a further once for all increase of $10 p e r$ cent in taxationthe major recommendation of the WB report and (c) a 10 per cent increase each year for loyears as was initially recommended in the draft WB report. Our methodology is set out in section I. The next section summarises the estimates whose derivation (together with the data) is provided in the Appendix.

\footnotetext{
1 Research support from BAT, U.K. is gratefully acknowledged.

2 A companion paper Lal (2000) provides a critique of this report using the results of this paper and also critically examines the so-called 'public health' viewpoint which has been claimed to undermine the economic calculus represented in this paper.
} 
I

The economic welfare effects of tobacco controls can be set out in terms of a simple supply- demand diagram, Fig. 1.

To simplify matters - and to avoid the problem of having to compute the effects on domestic production of various policies- assume that cigarettes can be bought at a given world price pw. These imports always supplement domestic supply, so that any change in domestic demand merely effects imports. With the existing taxes, the domestic price is pd, and the loss in consumer surplus (CS) is the area A $+B$, where the former gives the tax revenue, and the latter the deadweight loss associated with the tax.

If taxes are handed back to consumers in lump-sum fashion, or the value of a dollar of public funds is assumed to be at least equal to the value of a dollar to the consumer, then the tax burden A can be neglected as a social cost, and the net welfare cost will be the deadweight loss $B$. But the social value of this tax burden depends crucially upon the character of the government to whose coffers it accrues. If the government consists of Platonic Guardians then it is plausible to say that a dollar of public funds is worth more than a dollar of lost consumption, and in some cases could be worth even more. But if most governments, particularly those in the Third and second worlds are predatory (see Lal (1988), Lal-Myint (1996)), then the social value of this transfer of a dollar to the government will be less than a dollar and may even be worthless. Given the World Bank's ongoing crusade against corruption and for improved governance in many of its borrowers, implicitly it must ascribe the predatory rather than platonic end of this political spectrum to the character of the governments it advises. It would thus be best to look upon the tax burden as it is clearly to consumers - a burdenand which can only in special and specific cases and countries be set off as a social gain. We will therefore in our international comparisons eschew these political judgments and look upon the whole of the consumer surplus loss (CS= A+B) as a welfare loss to the consumer from taxation of cigarettes.

It should also be noted that the proposed taxation also violates the principles of horizontal and vertical equity recommended by traditional public finance principles. Horizontal equity requires equals should be treated uniformly. It is unfair to treat someone who is the same as everyone else, except for being a smoker, differently. Vertical equity requires that taxes should not be regressive. As the poor are predominantly smokers, tobacco taxes are inherently regressive. Against these principles of classical public finance which establish the case for uniform taxation, there is an argument based on modern public economics for non- 
uniform taxation which could be used in favour of tobacco taxation. This is the so-called Ramsey rule, which says that the excess burden of a tax (the deadweight consumer surplus loss (B) in Fig.1) is minimised by taxing goods in relatively inelastic demand- and the demand for tobacco is relatively inelastic. However, as Harberger

( 1987) has noted "to tax salt more heavily than sugar, simply and solely because it has a lower elasticity of demand is at least as capricious (from the standpoint of equity) as taxing people differently according to the colour of their eyes". Underlying these differences are different philosophies of government- the classical liberal view which favours neutrality defined as uniformity of taxation and the 'social engineering' view which defines it on the Ramsey principle.

What are the benefits from controlling tobacco? The most immediate is the reduction in cigarette consumption and the effects this may have on increased life expectancy. This is again a benefit which accrues to the consumer. What value can we impute to this possible extension of life? There has been an interminable and inconclusive debate on the value to be placed on human life and hence on the value of years of life saved ${ }^{3}$ Two things need to be noted in forming a judgment on this issue. First, the diseases and hence deaths resulting from smoking occur late in life and hence the costs associated will only occur if life expectancy is already fairly highwhich is in turn related to relative affluence. For many Third World countries where the traditional infectious diseases are still widespread and lower life expectancies, the smoker may well die off from other causes well before his smoking habit kills him. Here the World Bank reports egregious assumption that the normal life expectancy for everyone is that associated with the longest lived population - Japan's-allows it to define premature deaths from smoking in middle age to include deaths up to 69 years. A landless laborer in rural India would be surprised to learn that he is dying prematurely at the age of 69 because of his addiction to 'bidis'! Correspondingly the WB's headline grabbing figure of the 10 million lives to be saved by its tobacco crusade are not credible.

3 Chaloupka and Warner (1999) provide a comprehensive survey though with an irritating politically correct 'spin' of the economics of smoking, which provides references to this literature. The reason for the spin becomes clear when it is noted that Chaloupka is credited as the co-leader of the team which produced the World Bank report! For the illogicalities in the attempts made to provide some quantifiable measure of the closely related QALYs (quality of life years) and DALYs (disability adjusted life years) saved by various medical interventions see Broome (1993) and Lal (1994). 
Second, just as in national income accounting-despite the various complaints that have been made over the years that it does not provide a true measure of welfare (largely because of its neglect of distributional considerations - see LalMyint (1996))- GDP per capita remains a fairly robust and objective measure of at least the wealth of nations, the actual income and equivalent consumption lost as a result of reduced life expectancy is the simplest and most readily defensible value to be placed on the benefits of tobacco control. This is the measure we will use in deriving our estimates in Section 2 .

Are there any other costs and benefits? For developed countries with publicly funded health care and pension systems various additional social costs and benefits have been identified. For the US, for instance, it has been estimated (Viscusi (1998)) that in 1993 the social costs and benefits were as follows: Social costs- medical care $\$ 0.55$, sick leave $\$ 0.01$, group life insurance $\$ 0.14$, fires $\$ 0.02$, second hand smoke $\$ 0.25$, local taxes on earnings foregone $\$ 0.40$. Total costs to society were therefore $\$ 1.37$. Social Benefits- nursing home savings $\$ 0.23$, pensions and social security payments saved $\$ 1.19$, excise taxes paid $\$ 0.53$. The total social benefits were $\$ 1.95$, yielding a net social benefit of $\$ 0.58$ per pack of cigarettes. If, as we see below, the wholly spurious social costs of second hand smoke of $\$ 0.25$ are disregarded, the net social benefit rises to $\$ 0.83$ per pack!

For developing countries, as the World Bank report accepts, most of these purported social costs and benefits are irrelevant as they do not have extensive publicly or group funded health, insurance and pension systems. Apart from second hand smoke, most of the other social costs and benefits adduced above are privately borne. Also this estimate takes no account of the consumer surplus changes associated with smoking and its taxation. Moreover, even for developed countries most of the adduced social costs and benefits are pecuniary externalities which are Pareto irrelevant (see Buchanan and Stubblebine). Thus, as in standard cost-benefit analysis, all transfers including those relating to pensions, life insurance etc should be netted out. This leaves only the true external costs namely the costs associated with environmental smoke and probably from fires. As the latter are fairly small, we will ignore them, so that the only truly Pareto- relevant external effect - if it was proven- would be second hand smoke which damaged the health of others. In fact the moral crusade against tobacco in the West has been fuelled by the claims made in a US Environmental Protection Agency report in 1992, which claimed there was scientific evidence of health damage from passive smoking. This was thoroughly discredited by a US federal court in 1998 
for being inherently biased. ${ }^{4}$

As the only source of Pareto-relevant externalities remains damage from secondary smoke, it maybe useful to summarize the available evidence on this. This evidence is based on epidemiological studies. Gori and Luik's (1999)'s survey of all the available environmental tobacco smoke studies shows (see their Tables 11, 12, 13) that the evidence from spousal studies, those of non-smokers exposed to smoke in the work place and of children exposed to ETS shows: no increased risk to non-smokers, and for work place and childhood exposure suggest reduced risk or protection (p.43).5

The WB report's claim that the health effects include " disease in children and adults chronically exposed to second hand smoke" (p.32) is therefore unjustified. While its claim that the other effects "include low birth weight and increased risk of various diseases in the infants of smoking mothers" even if true provides no basis for taxing tobacco. There are numerous risks that infants face, the most important arising from poverty- and particularly in developing countries from infectious diseases and unsafe water supplies. Should the poor then be taxed for having babies because of the differential health costs their children will have to bear?

Thus there is no credible Pareto- relevant externality ${ }^{6}$ (see Buchanan and Stubbelbine) arising from smoking, and no need to go beyond the private costs and benefits we have already taken into account. The WB- WHO reports argument that there is a nuisance from tobacco smoke which is an externality is absurd. ${ }^{7}$ There are many things which individuals do which others find annoying and irritating. For instance some find the smell of cheap perfume very irritating. But that is no reason to ban or tax it. In fact much of civilization has evolved as a system of manners which allow many personal habits to be self-controlled in public places (see Elias). Most civilizations thus teach

4 The judgement is given in full in Gori and Luik (1999), and provides a devastating critique of this report.

5 The biological reason for this is that many toxins are beneficial in small doses, eg. toning up the immune system through immunisation. see R.M.Neese and G.C.Williams: Why we get sick.

Pareto relevant externalities are sometimes called 'technological' externalities which are not mediated through the price mechanism in contrast with pareto irrelevant externalities also called 'pecuniary' which are so mediated.

7 It writes: "Other direct costs" to non-smokers "include irritation and nuisance from smoke and the cost of cleaning clothes and furnishings" (p.32)! 
children not to break wind in public and to feel a sense of shame when they do. With divergent tastes and habits, the purpose of these manners is to allow us all to move in the communal spaces we inhabit with consideration for others. Not taxation or prohibition is the answer to the annoyance of tobacco for nonsmokers, but perhaps a course from Miss Manners in which smokers learn to ask in a public space : "Do you mind if I smoke".

Equally, tendentious is the Report's claim that consumers of tobacco in developing countries are ill informed of the risks involved. The best empirical study found that in the US, smokers over estimated the risks of smoking (Viscusi (1992)). The Report cites no evidence for its claim. But even if it were true this would merely justify a public information program, not taxation or prohibition.

The argument that cigarettes are addictive and thus pose a special risk to the young is also without any merit. The addictive nature of tobacco can be taken into account in estimating the demand, as is done in our estimates (See appendix). That the young should be saved from risky behavior which only hurts themselves, because they habitually underestimate the risks would mean banning them from all risky activity such as bungee jumping, riding, boxing, skate boarding, rugby and much more. Moreover, as the report notes that much of teenage behavior is based on rebellion, and as the evidence on the effects of bans and price increases in preventing teenage initiation into the tobacco habit is at best equivocal, ${ }^{8}$ perhaps instead the rebellious urge could be put to use- by adults telling children how nice cigarettes are instead of how nasty!

It should be clear that as far as the economic welfare effects of tobacco policies are concerned, for the developing world we do not need to go beyond the simple net consumer surplus change measure we presented at the outset.

\section{I}

We have derived estimates of the net economic welfare effects of taxation of cigarettes in the technical appendix for 5 countries/regions for which we are able to get the relevant data. Three of these are developing countriesIndia, Korea and South Africa. The arguments we have given for ignoring the social costs and benefits associated with public pensions and health systems are readily applicable to these countries. In addition we have also provided estimates for two developed countries/regions: Japan and the European Union (the 9 major countries in it viz.Belgium, Denmark, France, Germany, Ireland, Italy, Netherlands, Spain and the United Kingdom).

8 see the references to these studies in Chaloupka and Warner, though for the reason given earlier their assessment of these studies is dubious. 
These estimates too are derived on the same basis as for the developing countries. They can be interpreted as the true social costs and benefits net of transfer payments, or if the current erroneous practice of taking account of pecuniary externalities is maintained as the effects which would occur if the public health and pension systems were privatized and individuals bore the relevant costs and benefits themselves.

In deriving these estimates we have to take account of the addictive nature of cigarettes in estimating their demand. Till recently most estimates of cigarette demand were based on assuming consumers were irrational or myopic. In the irrational case (see eg. Schelling (1978)) a sort of divided self was posited, with stable but inconsistent preferences with the 'short run' self adoring tobacco while the 'long run' self wanted clean lungs and a long life. In the myopic models, current consumption depends on the 'stock of habits' which is given by the depreciated sum of all past consumption (see eg. Houthakker and Taylor (1966)). So current consumption depends on past consumption but not future consumption. The rational addiction models repair this omission and show how, even with addictive goods, consumers maximise utility over their life cycle taking account of the future consequences of their action (see Becker and Murphy (1988), Becker et.al. (1991)). These models capture many of the well known features of addiction to tobacco. Due to reinforcement, consumption in adjacent time periods are complements. So that current consumption of the good is related not only to the current price but also all past and future prices. The long run effect of a permanent price change will exceed that in the short run, as will that of an anticipated price change from one which is unanticipated. These models also lead to bimodal distributions of consumption echoing the 'binge' and 'cold turkey' type behaviour found among addicts. Also the model implies that temporary events like a price cut, peer pressure, stress etc can lead to permanent addiction. Finally, the responsiveness to price changes will also depend upon the individual's rate of time preference- the rate at which he/she discounts the future. The rational addiction model would thus seem to capture all the features that supposedly make cigarettes 'different' from other consumption goods.

We have estimated our demand curves for the five countries and regions for both the myopic and rational addiction models, and invariably the latter performs better. So our estimates of the welfare effects of tobacco taxation is based on the estimated rational addiction demand curves for each of our countries.

Next we estimated the consumer surplus (CS) lost per smoker as a result of the current level of taxation, i.e. the area $A+B$ in Fig. 1. With unchanging income, this CS annual 
loss would accrue for each of the year's the consumer continues to smoke. Assuming that most addicts get hooked on their habit at the age of 20 and then never give up, this gives us CS losses in the years till they die of their smoking related diseases. This does not take account of those smokers who quit, as we do not have any data on this.

Manning et al (1989) have used data from the Centre of Disease Control and US life tables to estimate the relative risk of smoking for two hypothetical cohorts of men and women from age 20 to death: one cohort smokes, the other does not. From this they derive the figure that, for each pack of cigarettes smoked, life expectancy at age 20 declines by 137 minutes. We use this figure to estimate the duration of life saved by the reduction in tobacco consumption caused by the current tax rates. As explained in section one, we value this savings in terms of the yearly per capita income (y (T)) that the person would have had if they had lived their normal life expectancy (E). So for each pack not consumed, at the date $\mathrm{T}=\mathrm{E}-20$ (as we assume that all our smokers start at 20

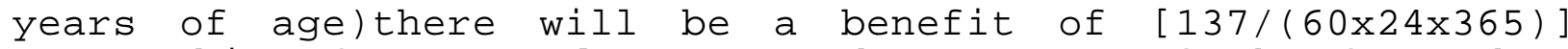
$y(T)$. This of course does not take account of the fact that with cigarettes there are threshold effects as at a low daily consumption, numerous studies have found that, there maybe no significant risk for smokers as compared with non-smokers (see Gori and Mantel (1991))

Without any income growth, therefore, the net welfare benefit of the tobacco taxes will be: the CS losses from age 20 till the normal life expectancy in that country, against which have to be set the benefits of the extra years of life gained (valued at the per capita income) in the year $\mathrm{T}$. But as a dollar given up today is not equivalent to a dollar gained tomorrow, we will have to discount these dated costs and benefits. The rational addiction model estimates, provide the rates at which our average smoker discounts the future, but to take account of the 'misperception of risk' argument currently used against smoking, we will be using much lower 'social' discount rates, namely 2,5 , and 10 per cent to determine the net present values from the alternative levels of taxation of cigarettes.

Finally, we need to take account of the fact that per capita income will increase in the future. This will effect both the costs and benefit calculations. In terms of Fig. 1, the demand curve will now shift in each year because of income growth. So in each year we will have the additional consumer surplus loss given by area $C$ added on. This is readily derived from our demand curve estimates. Also the per capita income in year $\mathrm{T}$ when the benefits from increased life accrue will also be higher.

If $n$ is the percentage of a year saved by not smoking a pack of cigarettes, and per capita income is 
growing at the rate of $g$ per year, and $d$ is the discount rate, then the present value of the benefits (PVB) from tobacco taxation is the reduction in cigarette packs per smoker (N) induced at our assumed starting age of 20, so:

$$
\mathrm{PVB}=\mathrm{N} \cdot\left[\mathrm{n} \cdot \mathrm{y}(1+\mathrm{g})^{\mathrm{T}}\right] /(1+\mathrm{d})^{\mathrm{T}}
$$

The present value of the consumer surplus (PVC) lost in each year $C^{\mathrm{n}}$ is :

(2) $\quad \mathrm{PVC}=\mathrm{N} \cdot\left[_{\mathrm{n}=0}{ }^{\mathrm{T}} \quad \mathrm{C}^{\mathrm{n}} /(1+\mathrm{d})^{\mathrm{n}} \quad\right]$

The net present benefit NPB is then given by:

(3) $\mathrm{NPB}=(1)-(2)$

In the Appendix these estimates have been made for (a) the current level of taxation in each of the 5 countries (b) a 10\% increase in taxation as recommended by the WB report (c) a 10\% increase p.a. for 10 years as recommended in the draft WB report.

Table 1, summarises the estimates for each of these policies for each of the countries on the best guesses about the likely value of $g$, and assuming $d=2$. We give the figures for each smokers change in welfare, and for the country in aggregate. The per capita income and GDP is also given for each country to allow a comparison of these net benefits to be appropriately scaled.

By any standard, the economic welfare losses from existing tobacco taxes are huge, and will further rise if the taxes are raised on either of the two policy recommendations. Thus for Korea the per smoker loss from current taxation is nearly 15\% of current per capita income, and the aggregate loss from current and future taxation (of a $10 \% \mathrm{p} . \mathrm{a}$. increase for 10 years) would amount to $12 \%$ of current GDP. For India, the per smoker loss from current taxation is nearly twice per capita GDP, and the aggregate loss from current and future taxation (of a $10 \%$ increase for 10 years) would be a massive 80\% of current GDP. For South Africa, the per smoker loss from current cigarette taxation is about 11\% of per capita income, and the aggregate loss from current and future taxation (of a 105 increase for 10 years) is $41 \%$ of current GDP.

As the smokers who incur these losses are admitted by the WB report to be relatively poor, and if we were to apply the WB's project evaluation methodology (Squire and van der Tak), we would have to apply distributional weights to them, so that a 1 \$ loss to these poor would be socially more costly than a 1 \$loss to some one at the per capita income. We have not made this adjustment as we do not have any income distributional data on smokers. But this does suggest that our estimates are likely to be under-estimates of the true social losses from tobacco taxation in developing countries. 
TABLE 1 SUMMARY OF NET ECONOMIC BENEFITS OF CIGARETTE TAXES NET PRESENT VALUES (US \$)

COUNTRY/REGION YEAR

INCREASE FOR

\section{YEARS}

---------------

$-----$

I. KOREA

( $2 \% \mathrm{pa}$. y incr, $d=2 \%)$

(a) per smoker 2463

(b) aggregate $-37$
CURRENT

TAXES

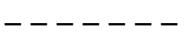

$10 \%$ INCREASE

$10 \div \mathrm{a}$

10

per capita income: 10,641; GDP (billions): 489.38

II. INDIA

( $3 \circ \mathrm{p} \cdot \mathrm{a} \cdot \mathrm{y}$ incr, $d=2 \%$ )

$-280$

(a) per smoker

$-455$

$-20$ 
61.69

(b) aggregate (billions) - $99.9 \quad-5.64$

per capita income: \$209; GDP (billions) : \$196.23

III. SOUTH AFRICA

(3\%p.a, y incr.

$d=2 \%)$

2104

92.8

(a) per smoker $\quad-822 \quad-153$

(b) aggregate (billions) $\quad-36.3 \quad-6.8$

per capita income: 7186; GDP (billions) 316.9

IV. JAPAN

$(2 \% \mathrm{pa}, \mathrm{y}$ incr.

$d=2 \%)$

4309
(a) per smoker
$-3190$
$-529$

$-273$

(b) aggregate (billions) -106

$-18$

per capita income:29,404; GDP (billions): 3717

V. EUROPEAN UNION ( 9 countries)

$(0 \% \mathrm{p} . \mathrm{a}, \mathrm{y}$ incr.

$d=2 \%$ )

6597

(a) per smoker

$-1998$

$-354$

$-900$

(b) aggregate (billions)- 273

per capita income: 17,697; GDP (billions): 5892

Source: Appendix Tables.

G.Becker and K. Murphy (1988): "A theory of rational addiction", $\quad$ Journal of Political Economy, 96: 
$675-700$

G.Becker, M.Grossman, K. Murphy (1994): "An empirical analysis of cigarette addiction", american Economic Review, 84: 396-418.

J. Broome(1993): "QALYS", Journal of Public Economics, 50: $149-67$.

J. Buchanan and W.C.Stubblebine (1962): "Externality",
$\begin{aligned} & \text { Economica } \\ & 29: 371-84.7\end{aligned}$

F.J. Chaloupka and K.E.Warner (1999): "The Economics of Smoking", $\quad$ NBER Working Paper No. 7047, NBER, Cambridge Mass.

N.Elias (1978): The Civilising Process, 2 vols., Pantheon, New York.

G. B. Gori (1998): "Epidemiology and public health: is a new 51: $\quad 637-41$.

G.B.Gori and J.C. Luik (1999): Passive Smoke, Fraser Institute, $\quad$ Vancouver.

G.B.Gori and N. Mantel (1991): "Mainstream and environmental tobacco smoke", Regul Toxicol Pharmacol, 14: 88-105.

A.C.Harberger (1987): "Neutral Taxation", The New Palgrave, $3: 645-$

7 .

H. Houthakker and L. Taylor (1966): Consumer Demand in the United States 1929-1970, Harvard University Press, Cambridge Mass.

D. Lal (1998): The Hindu Equilibrium, Clarendon Press, Oxford.

D.Lal (1994): "The role of the public and private health sectors in health financing in developing countries", HRO Working paper, no.33, The World Bank, Washington D.C. reprinted in Lal (1999)

D.Lal and H. Myint (1996): The Political Economy of Poverty, Equity and Growth, Clarendon Press, Oxford

J. Le Fanu (1998): The Rise and Fall of Modern Medicine, Harper Collins, London.

W.G. Manning et al. (1989): "The Taxes of Sin", JAMA, 261: $1604-9$. 
T.C. Schelling (1978): "Egonomics, or the art of selfmanagement", American Economic Review, 68: 290-4.

L.Squire and H. van der Tak (1975): Economic Analysis of Projects, Johns Hopkins, Baltimore.

K.Viscusi (1992): Smoking, Oxford University Press, New York. World Bank (1999): Curbing the Epidemic, World Bank, Washington D.C.

World Health Organisation (1999): The World Health Report 1999, Oxford University Press, Oxford.

------- (2000): "Provisional texts of proposed draft elements for a WHO framework convention on tobacco control", Who website, A/FCTC/WG2/3, 29 February 2000. 